\title{
EFEKTIVITAS PEMBELAJARAN KOLABORATIF PADA MATA KULIAH PEMBELAJARAN MATEMATIKA BERBASIS INFORMATIKA
}

\author{
Ratih Handayani \\ Program Studi Pendidikan Matematika, FKIP Universitas Muhammadiyah Kotabumi \\ email: ratihhandayani12@gmail.com
}

\begin{abstract}
This research was investigated about the effectiveness of colaborative learning on Mathematics based Informatics which aimed at probing whether the use of Colaborative Learning in Mathematic Departement of University of Muhammadiyah Kotabumi is effective to be used on Mathematics based Informatics subject. The method used was decriptive quaitative. The colaborative learning was implied on the lesson plan design and during the learning process in 8 meetings consisting of 16 students as the research sample. Based on the research result, it was found that the use of colaborative learning is effective to be used on Mathematics based informatics subject.
\end{abstract}

Keyword: PDS, Collaborative Learning, Mathematics based Informatics subject.

\section{PENDAHULUAN}

Program Penugasan Dosen ke Sekolah (PDS) adalah salah satu hibah yang diberikan pemerintah kepada Lembaga Pendidikan Tenaga Kependidikan (LPTK) guna peningkatan kualitas penyiapan calon guru profesional. Pada tahun 2018 Direktorat Pembelajaran melaksanakan hibah revitalisasi LPTK dengan fokus pada kemitraan antara LPTK dan sekolah laboratorium dan/atau Sekolah Laboratorium dan/atau Sekolah Mitra yang saling mendukung, yaitu berupa penugasan dosen ke sekolah.

Keberhasilan PDS di tahun 2018, memberi pengalaman yang bermanfaat bagi dosen untuk memperbaiki kualitas pembelajaran di LPTK sehingga secara langsung hasilnya pun dapat dirasakan oleh mahasiswa. Berdasarkan hasil pada penugasan ke sekolah, dosen perlu mengevaluasi perkuliahan yang telah berlangsung dan melakukan pembaruan pembelajaran agar sesuai dengan kondisi nyata pembelajaran di sekolah. Hal ini akan menyiapkan mahasiswa untuk mengikuti kegiatan magang pembelajaran di sekolah.

Untuk menerapkan pengalaman yang telah diperoleh tersebut maka pada tahun 2019 dikembangkan program lanjutan PDS di LPTK yaitu program PDS Skema B. Tujuan dari program implementasi PDS skema B yaitu:

1. Dosen menerapkan pengalaman terbaik ketika mengikuti program PDS pada tahun 2018 pada perkuliahan 
yang diampu di prodi yang bersangkutan.

2. Dosen menerapkan hasil kemitraan dengan guru di sekolah pada PDS 2018 dalam perkuliahan yang diampunya di prodi yang bersangkutan.

3. Dosen menciptakan suasana yang mendukung peningkatan kualitas calon guru melalui perkuliahan yang diampunya di prodi yang bersangkutan.

4. Dosen meningkatkan kualitas pembelajaran pada program studi kependidikan dalam menunjang program pendidikan guru di LPTK

Kegiatan PDS di STKIP Muhammadiyah Kotabumi dilaksanakan salah satunya pada mata kuliah Pembelajaran Matematika Berbasis Informatika. Mata kuliah Pembelajaran Matematika Berbasis Informatika adalah mata kuliah wajib pada Program Studi Pendidikan Matematika. Mata kuliah ini bertujuan agar mahasiswa mampu mampu memanfaatkan teknologi yang berkembang saat ini untuk mendesain pembelajaran matematika dengan berbagai software yang tersedia dan pada akhirnya mahasiswa mampu membuat media pembelajaran matematika dengan menggunakan berbagai software tersebut.

Materi yang dipelajari pada mata kuliah ini sifatnya adalah teori dan praktik bukan hitung-hitungan seperti lazimnya mata kuliah matematika lainnya maka bentuk perkuliahan pada mata kuliah ini adalah menggunakan presentasi. Tugas pada mata kuliah ini bersifat open ended. Tugas dikerjakan secara berkelompok, yang dapat diawali dengan pengerjaan tugas individu, kelompok kecil, kemudian kelompok besar. Pada bentuk perkuliahan dengan tugas seperti ini pembelajaran kolaboratif diperlukan karena Input utama pada pemebelajaran kolaboratif adalah tugas yang bersifat open ended. Selain itu pemeblajaran kolaboratif juga dapat membuat mahasiswa bersama-sama membangun pemahaman materi yang akan dipelajari.

Berdasarkan uraian tersebut maka akan dilakukan penelitian bagaimana efektivitas pembelajaran kolaboratif pada mata kuliah pembelajaran matematika berbasis informatika

\section{KAJIAN TEORI}

Mata kuliah Pembelajaran Matematika Berbasis Informatika adalah salah satu mata kuliah wajib pada program studi pendidikan matematika. Deskripsi dari Mata kuliah ini adalah mendesain pembelajaran matematika dengan menggunakan berbagai software dan pada akhirnya mahasiswa mampu menciptakan suatu bahan ajar atau media pembelajaran yang menggunakan software yang tersedia. Software yang dapat digunakan dalam pembelajaran ini antara lain macromedia 
flash atau adobe flash. Flash cocok digunakan karena aplikasi ini mudah untuk dipelajari bagi pemula. Ardiyansyah (2013:7) menambahkan keunggulan, yaitu tidak perlu memiliki kemampuan sebagai programmer untuk membuat film flash. Jadi, software ini dapat digunakan berbagai kalangan.

Flash menurut Hidayat (2013) adalah aplikasi yang didesain dengan kemampuan untuk membuat animasi 2 dimensi yang handal dan ringan sehingga flash banyak digunakan untuk membangun dan mem-berikan efek animasi pada website, $\mathrm{CD}$ Interaktif dan yang lainnya. Selain itu aplikasi ini juga dapat digunakan untuk membuat animasi logo, movie, game, pembuatan navigasi pada situs web, tombol animasi, banner, menu interaktif, interaktif form isian, e-card, screen saver dan pembuatan aplikasi-aplikasi web lainnya.

Dalam Flash, terdapat teknik-teknik membuat animasi. Teknik-teknik inilah yang akan dipelajari pada mata kuliah pembelajaran matematika berbasis informatika. Flash akan membuat kreativitas mahasiswa akan berkembang. Karena dalam proses pembuatan animasi dibutuhkan kreativitas agar media yang dihasilkan tidak hanya baik secara konsep materi tetapi juga menarik perhatian peserta didik. Sehingga diharapkan pembelajaran matematika kelak akan berbasis teknologi dan menyenangkan.

Kemampuan akhir yang diharapkan dari mata kuliah ini sangat bermanfaat bagi calon guru lulusan program studi pendidikan matematika, karena kemampuan ini berkaitan langsung dengan pembelajaran matematika disekolah dan sebagai bekal ketika mereka akan melaksanakan magang pembelajaran di sekolah.. Maka sebagai LPTK penghasil calon guru, Universitas Muhammadiyah Kotabumi akan berusaha meningkatkan kualitas pembelajaran dengan mengembangkan kurikulum sesuai dengan kebutuhan lokal pada mata pelajaran matematika di sekolah.

Kegiatan pengembangan kurikulum pada mata kuliah pembelajaran matematika berbasis informatika dilakukan dengan melakukan pembelajaran kolaboratif. Pada pembelajaran kolaboratif tidak seperti belajar sendirian, orang yang terlibat dalam pembelajaran kolaboratif akan memanfaatkan sumber daya dan keterampilan satu sama lain misalnya dalam hal meminta informasi satu sama lain, mengevaluasi ide-ide satu sama lain, memantau pekerjaan satu sama lain, dll.

Menurut Barkley (2014:4) berkolaborasi berarti bekerja bersama-sama dengan orang lain. Selanjutnya, Pijls et. al (2006) menjelaskan bahwa ada empat kunci kegiatan pembelajaran kolaboratif yang dapat meningkatkan kemampuan 
matematika siswa, yaitu menunjukkan hasil pekerjaan satu siswa, menjelaskan hasil unjuk kerjanya, pemberian masukan dan saran dari siswa yang lain, dan menyusun kembali hasil kerjanya sesuai dengan masukan dan arahan. Howe (2007) menyatakan bahwa pembelajaran kolaboratif dinilai produktif ketika guru hanya mengambil sedikit intervensi dan membiarkan siswa melatih kemampuannya dalam menyelesaikan masalah yang disajikan dalam pembelajaran.

Kolaborasi yang akan dilakukan dalam penelitian ini adalah kolaborasi antara dosen pengampu mata kuliah Pembelajaran Matematika Berbasis Informatika Universitas Muhammadiyah Kotabumi dengan mahasisawa semester V program studi pendidikan matematika. Hal yang akan dikolaborasikan adalah proses pembelajaran di kelas, misalnya pada penyusunan materi pembelajaran dan pada saat penyampaian materi.

\section{METODOLOGI PENELITIAN}

Metode yang digunakan dalam penelitian ini adalah deskriptif kualitatif. Metode deskriptif kualitatif menurut Sugiyono (2010:15) adalah metode penelitian yang berlandaskan pada filsafat positivisme, digunakan untuk meneliti pada kondisi obyek yang alamiah, (sebagai lawannya adalah eksperimen) dimana pe- neliti adalah sebagai instrumen kunci, pengambilan sampel sumber data dilakukan secara purposive dan snowbaal, teknik pengumpulan dengan trianggulasi, analisis data bersifat induktif/kualitatif, dan hasil penelitian kualitatif lebih menekan makna dari pada generalisasi. Penelitian kualitatif merupakan penelitian yang berhubungan dengan ide, persepsi, pendapat, kepercayaan orang yang akan diteliti dan kesemuanya tidak dapat di ukur dengan angka. Yang menjadi subjek penelitian adalah mahasiswa semester $\mathrm{V}$ dengan jumlah 16 orang. Teknik pengumpulan data diperoleh dari hasil observasi dan catatan lapangan yang dilakukan oleh para observer.

\section{HASIL DAN PEMBAHASAN PENELITIAN}

Pembelajaran kolaboratif dilakukan dimulai dari awal perkuliahan yaitu ketika penyusunan materi ajar pada RPS. Dosen menyampaikan deskripsi mata kuliah dan kemampuan akhir yang harus dikuasai oleh mahasiswa. Dalam menyusun deskripsi dan kemampuan akhir, dosen telah berkolaborasi dengan dosen rumpun ilmu yang sama dengan memperhatikan kebutuhan peserta didik di sekolah ketika dosen mengikuti kegiatan PDS ditahun 2018. Berbekal hal itu dosen dan mahasiswa berkolaborasi untuk menen- 
tukan materi apa saja yang akan dipelajari, bagaimana bentuk perkuliahan yang efektif pada mata kuliah ini serta pembagian materi ajar yang akan dipresentasikan.

Setelah materi pembelajaran dan bentuk pembelajaran dengan presentasi telah disepakati maka pelakasanaan pembelajaran diawali dengan dosen menjelaskan garis besar materi ajar, sehingga mahasiswa memiliki persepsi yang sama terhadap materi ajar dan mahasiswa dapat menentukan dan mencari dengan jelas materi yang akan mereka presentasikan. Berikut adalah salah satu dokumentasi ketika dosen menjelaskan garis besar materi ajar.

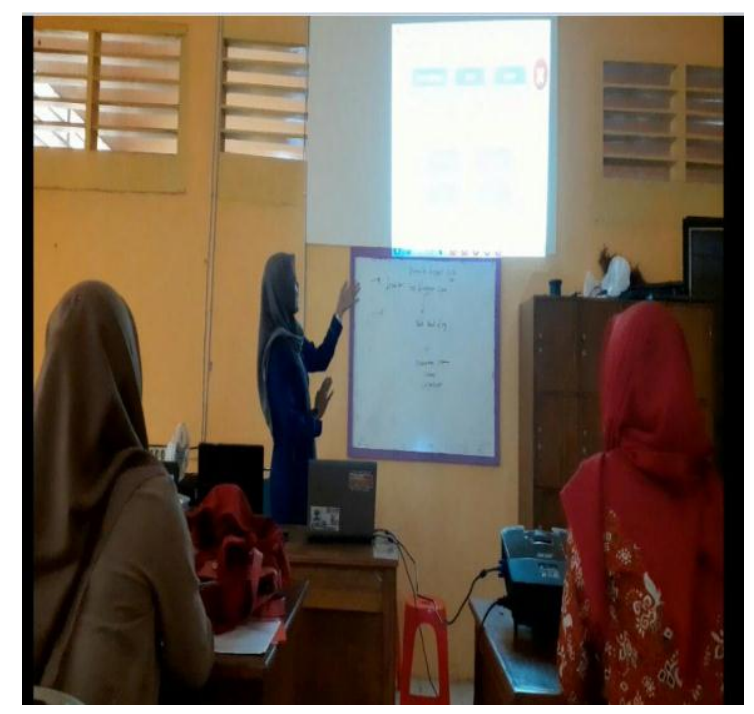

Gambar 1.

Dosen menjelaskan materi ajar

Setelah pembagian materi pembelajaran disepakati, maka dibentuk kelompok yang akan menjelaskan materi-materi tersebut. Pada pertemuan berikutnya setiap kelompok akan berkolaborasi dengan anggota kelompoknya untuk menentukan dan mencari materi yang akan mereka buat media pembelajarannya untuk kemudian mereka presentasikan berikut referensinya. setelah itu setiap kelompok akan berkolaborasi dengan dosen untuk mengembangkan materi yang telah disusun oleh mahasiswa. Sehingga pada akhirnya materi yang akan disampaikan adalah materi yang sesuai dengan tujuan pembelajaran tetapi materi tersebut disusun dan dikembangkan bersama oleh dosen dan mahasisawa.

Setelah materi disepakati, pertemuan berikutnya mahasiswa mulai belajar dengan menggunakan bentuk presentasi. Presentasi yang pertama adalah, mahasiswa akan menjelaskan teknik-teknik dalam menggunakan macromedia flash. Mahasiswa sebagai pemakalah akan menjelaskan bagaimana membuat media pembelajaran menggunakan macromedia flash. Materi yang bersifat teori yang disampaikan oleh pemakalah akan langsung dipraktikkan oleh rekan-rekan mahasiswa yang lain, dan apabila terjadi kesulitan maka mahasiswa akan langsung berdiskusi untuk menyelesaikan masalahnya. Kolaborasi sesama mahasiswa ini akan memudahkan mereka untuk lebih memahami materi yang dipelajari. Dan mahasiswa lebih nyaman dalam berinteraksi karena tidak ada perasaan untuk saling menggurui.

Pada saat mempraktikkan teknik 
yang diajarkan, setiap kelompok membutuhkan kreativitas dan ide-ide dari anggota kelompoknya, untuk dapat membuat media pembelajaran yang menarik, karena kemampuan mereka dalam membuat media pembelajaran ini akan bermanfaat keetika mereka akan melaksanakan kegiatan magang pembelajaran di sekolah. Berikut adalah gambar ketika mahasiswa berkolaborasi dengan sesama mahasiswa ketika pembelajaran berlangsung.

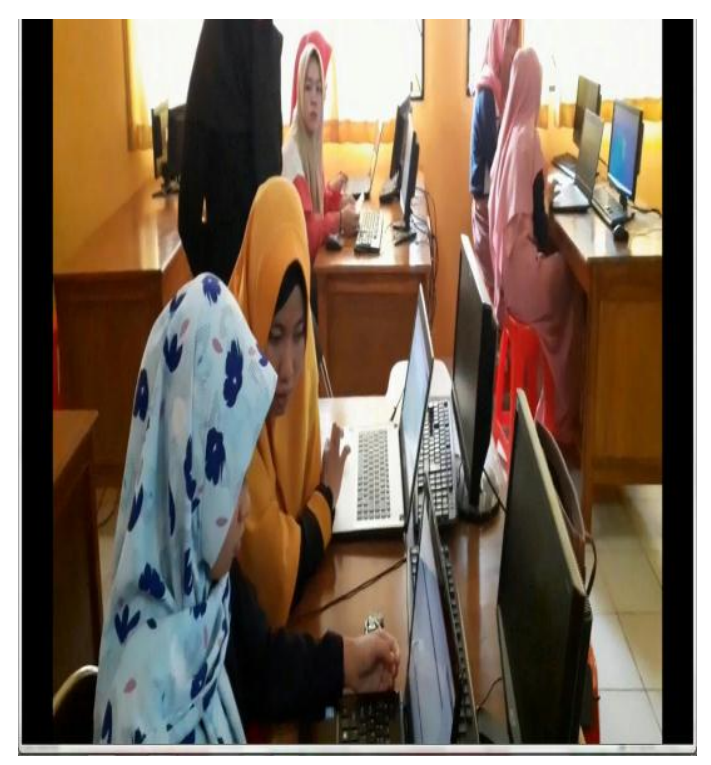

Gambar 2.

Kolaborasi dalam pembelajaran

Setelah mahasiswa menguasai materi terkait pembuatan media dengan macromedia flash, maka mahasiswa akan mengaplikasikannya dalam pembuatan bahan ajar yang akan mereka terapkan ketika mengikuti kegiatan magang pembelajaran disekolah. Masing-masing kelompok akan memilih satu subbab materi matematika di sekolah, lalu materi tersebut akan dibuat media pembelajarannya dengan menggunakan macromedia flash. Setelah berhasil membuat media pembelajaran dilanjutkan dengan mempresentasikan hasil kerjanya dihadapan rekan-rekan mahasiswa dan tetap akan berkolaborasi guna mendapatkan media yang lebih baik lagi.

Hal ini sesuai dengan yang disampaikan oleh Pijls et. al (2006) bahwa salah satu kunci kegiatan pada pembelajaran kolaborasi adalah menunjuk-kan hasil pekerjaan siswa. Presentasi atau unjuk kerja yang dilakukan mahasiswa adalah menayangkan hasil kerja mereka yaitu media pembelajaran matematika dengan materi yang telah disepakati sebleumnya.

Kunci pembelajaran kolaborasi berikutnya adalah menjelaskan hasil kerjanya. Mahasiswa akan menjelaskan bagaimana mereka membuat tayangan atau media pembelajaran tersebut. Dalam proses penjelasan tersebut ternyata ada mahasiswa yang membuat media pembelajaran tidak hanya menggunakan teknik yang selama ini disampaikan oleh rekan-rekan mahasiswa maupun dosen pengampunya. Mahasiswa aktif dalam mencari sumber referensi untuk membuat medianya tampil semenarik mungkin. Hal ini sesuai dengan yang disampaikna oleh Suryani (2010:9) bahwa dalam pem- 
belajaran kolaboratif bukan tidak mungkin ada kalanya siswa mengajar gurunya juga.

Kunci pembelajaran kolaboratif yang ketiga adalah pemberian masukan dan saran dari mahasiswa lain dan dosen. Ketika mahasisawa menjelaskan hasil kerjanya, kolaborasi terjadi antara sesama mahasiswa juga dengan dosen pengampu. Kolaborasi terjadi dalam bentuk tanya jawab. Misalnya ada teknik yang tidak diajarkan oleh dosen pengampu maupun rekan mahasiswamya, tetapi digunakan oleh pemalakah dalam pembuatan medianya, dan itu menjadikan medianya lebih menarik. Hal itu menjadi bahan diskusi yang menarik bagi mereka.

Selain pertanyaan, masukan juga diberikan audience kepada pemakalah. Misalkan ada konsep yang belum tersampaikan dengan baik atau ada tampilan yang menurut audience mengganggu. Berbagai masukan dan pertanyaan diberikan oleh mahasiswa dan dosen pengampu terhadap media pembelajaran tersebut digunakan oleh pemakalah sebagai bahan untuk revisi selanjutnya. Kegiatan merevisi bahan ajar sesuai masukan dan arahan merupakan kunci pembelajaran kolaboratif yang terakhir.

Hasil evaluasi dari pembelajaran ini adalah mahasiswa mampu mendesain sebuah media pembelajaran matematika yang menarik. Proses pembuatan media pembelajaran ini menggunakan pembelajaran kolaboratif yang melibatkan dosen dan mahasiswa. Kolaborasi ini dilakukan dari awal perkuliahan hingga akhir perkulihan sehingga tercipta suatu media pembelajaran yang baik secara konsep dan menarik tentunya sebagai bentuk kreativitas mahasiswa dan sesuai dengan kebutuhan lokal peserta didik.

\section{SIMPULAN}

Berdasarkan hasil penelitian yang dilakukan maka pembelajaran kolaboratif pada mata kuliah pembelajaran matematika berbasis informatika dapat membantu dosen dan mahasiswa untuk saling belajar. Saling belajar bagaimana mendesain dan menciptakan media pembelajaran yang sesuai dengan kebutuhan lokal. Media Pembelajaran yang dihasilkan dapat digunakan oleh mahasiswa sebagai bahan ajar ketika pelaksanaan magang pembelajaran di sekolah. Dan pada akhirnya pembelajaran kolaboratif efektif digunakan pada mata kuliah pembelajaran matematika berbasis informatika. 


\section{DAFTAR RUJUKAN}

Ardiansyah, Nurdin. 2013. Tutorial Macromedia Flash Profesional 8 untuk Pemula.Tersedia.(https://inteleccreativemedia.files.wordpress.com/2014/04/macromedia-flash-8- nurdin.pdf) 8.

Elizabert E. Barkley, K. Patricia Cross, Clarie Howell Major. 2014. Collaborative Learning Techniques. Bandung: Nusa Media.

Hidayat, Fauzi. 2013. Modul Macromedia Flash 8. Tersedia. (http://ahmadfauzihidayat.blogspot.com/2013/03/modul-macromedia-flash-8.html)

Howe, C. J., Tolmie, A., Thurston, A., Topping, K., Christie, D., Livingston, K., et al. 2007. Group Work in Elementary Science: Towards Organizational Principles for Supporting Pupil Learning. Learning and Instruction.

Pijls, M., Dekker, R., Hout-Wolters, B.V. 2007. Reconstruction of Collaborative Mathematical Learning Process. Educational Studies in Mathematics.

Suryani, Nunuk.2010. Implementasi Model Pembelajaran Kolaboratif Untuk Meningkatkan Keterampilan 